\title{
Mechanical Behaviour and Primary Stability of a Self-Condensing Implant: A Laboratory Critical Simulation of a Severe Maxillary Atrophy on Polyurethane Lamina
}

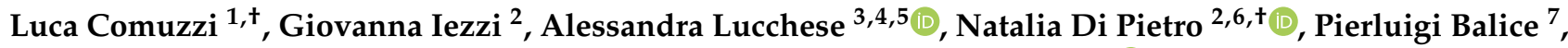 \\ Camillo D'Arcangelo ${ }^{2}$, Adriano Piattelli ${ }^{2,8,9,10}$ and Margherita Tumedei ${ }^{2, *(D)}$
}

Citation: Comuzzi, L.; Iezzi, G.; Lucchese, A.; Di Pietro, N.; Balice, P.; D'Arcangelo, C.; Piattelli, A.;

Tumedei, M. Mechanical Behaviour and Primary Stability of a Self-Condensing Implant: A Laboratory Critical Simulation of a Severe Maxillary Atrophy on Polyurethane Lamina. Appl. Sci. 2022, 12,966. https://doi.org/10.3390/ app12030966

Academic Editor: Gabi Chaushu

Received: 18 October 2021 Accepted: 29 November 2021 Published: 18 January 2022

Publisher's Note: MDPI stays neutral with regard to jurisdictional claims in published maps and institutional affiliations.

Copyright: (C) 2022 by the authors. Licensee MDPI, Basel, Switzerland. This article is an open access article distributed under the terms and conditions of the Creative Commons Attribution (CC BY) license (https:// creativecommons.org/licenses/by/ $4.0 /)$.
1 Independent Researcher, 31015 Conegliano, Italy; luca.comuzzi@gmail.com

2 Department of Medical, Oral and Biotechnological Sciences University, "G. D'Annunzio" of Chieti-Pescara, 66100 Chieti, Italy; gio.iezzi@unich.it (G.I.); n.dipietro@unich.it (N.D.P.); camillo.darcangelo@unich.it (C.D.); apiattelli@unich.it (A.P.)

3 Unit of Orthodontics, Division of Dentistry IRCCS San Raffaele Scientific Institute, 20132 Milan, Italy; lucchese.alessandra@hsr.it

4 Unit of Orthodontics, School of Dentistry, Vita-Salute San Raffaele University, 20132 Milan, Italy

5 Unit of Dentistry, Research Center for Oral Pathology and Implantology, IRCCS San Raffaele Scientific Institute, 20132 Milan, Italy

6 Center for Advanced Studies and Technology-CAST (ex CeSI-MeT), University G. D'Annunzio of Chieti-Pescara, 66100 Chieti, Italy

7 Department of Periodontics, University of Missouri-Kansas City, Kansas City, MO 64030, USA; pierluigi.balice@gmail.com

8 Biomaterials Engineering, Catholic University of San Antonio de Murcia (UCAM), Av. de los Jerónimos, Guadalupe, 135, 30107 Murcia, Spain

9 Fondazione Villaserena per la Ricerca, 65121 Città Sant'Angelo, Italy

10 Casa di Cura Villa Serena del Dott. L. Petruzzi, Via Leonardo Petruzzi 42, 65013 Città Sant'Angelo, Italy

* Correspondence: margytumedei@yahoo.it; Tel.: +39-0871-3554083

$+\quad$ These authors equally served as co-first authors.

\begin{abstract}
Background: Posterior maxillary atrophies could emerge after the loss of teeth, trauma, infections, or lesions that often require regenerative approaches. In these critical conditions, the achievement of implant primary stability represents a clinical challenge in the operative practice. Therefore, a two-stage approach is often preferred with a delay of the rehabilitation time and a consistent increasing of the biological and the operative costs. The aim of this study was to evaluate the mechanical behaviour of a self-condenser implant compared to a standard implant in a critical simulation on different thicknesses and densities of polyurethane lamina. Materials and methods: A total of two implant models were tested: a self-condensing device (test) and a standard implant (control). The study evaluated the insertion torque and the pull-out strength values of the test and control implants inserted in different sizes $(1,2$, and $3 \mathrm{~mm})$ and density polyurethane lamina $(10,20$, and 30 pcf) for a total of 320 experimental sites. Results: In total, 320 experimental sites were produced in the polyurethane samples. A statistically significant difference of insertion and pull-out torque values between the test and control Implants was found in the different bone densities $(p<0.05)$. The insertion and pull-out torque values were always higher for the test implants in all experimental conditions. In all bone densities, the insertion torque values were higher than the pull-out torque values. The self-condenser dental implant design evaluated in this in vitro study showed a high level of stability in all experimental conditions. Conclusions: The test implant could represent a useful tool for a one-stage surgical approach in the presence of limited residual native bone as an alternative to a delayed technique.
\end{abstract}

Keywords: maxillary atrophies; dental implant; primary stability; laboratory simulation 


\section{Introduction}

Currently, osseointegrated implants have a high long-term predictability associated to fixed oral rehabilitation [1]. The essential condition to support the functional loading of the dental implant is the creation of an intimate and dynamic relationship between the device surface and the vital surrounding bone [2,3]. This aspect is directly associated to the fixture primary stability, the bone tissue quantity and quality, the implant macro- and micro-design, the surface characteristics, and the thread profile and pitch, which represent key factors for implant osseointegration [2-6]. Bone density seems to be a critical factor for implants' primary stability. Misch et al. classified bone density into four different categories, based on the perception of the subjective operator during osteotomy perforation (D1 is the hardest and D4 the softest). It is a non-quantitative, subjective, and non-reproducible system [7]. In the literature, it was reported that the high predictability associated with oral implant rehabilitation is directly correlated to obtaining fixture primary stability and a successful functional healing of the osteotomy site. Many different dental implant and thread profiles have been proposed to achieve a favourable primary stability in low bone density [8]. The assessment of the quality of the bone structure must be considered as an essential procedure before the implant placement in order to avoid early bone failure and increase the success of the surgical procedure [9]. Posterior edentulous maxillary ridges are often associated with a lack of bone quantity and quality due to the proximity of the maxillary sinus. In this scenario, a regenerative approach is often required. The primary stability of the dental implant is considered in the literature as a key factor for the long-term predictability of endosseous implants under functional loading [5]. This concept is correlated to the absence of micromobility of the fixture when in contact with the bone substrate [10]. The primary stability is clinically determined by the mechanical relationships and interface engagement of the fixture with the cortical bone [11]. In fact, the bone-implant interface is influenced by the surgical technique [12] and the size of the implant, design, and micro-/macrotopography [13].

In this way, many different approaches have been described to improve the primary stability in critical density and bone availability: under preparation techniques [6,14], manual and stepped osteotomies [10], optimized implant micro- and macro-geometry, and thread profiles [15]. It is very important to quantify the stability of the implant at various times for a long-term prognosis. Therefore, the use of simple and clinically applicable non-invasive tests to evaluate implant stability and osseointegration can be considered useful [10,16-20]. In this way, many different non-destructive protocols have been reported in the literature for the primary stability assessment, for example insertion torque (IT) [21] and resonance frequency analysis (RFA) [22]. Polyurethane blocks in the form of standardized densities have been proposed for in vitro tests to simulate the consistency and the density of the bone [23].

The aim of the present study was to evaluate through a laboratory simulation the biomechanical behaviour of an implant with a special design proposed for a one-stage sinus augmentation compared to a standard implant.

\section{Materials and Methods}

\subsection{Polyurethane Foam Blocks}

Polyurethane foam could be an alternative useful material to provide mechanical tests for human bone. The American Society for Testing and Materials (ASTM F-1839-08) indicated the polyurethane blocks for standardized tests of dental implants according to their physical and mechanical properties [24]. In fact, polyurethane block simulation is able to avoid the disadvantage correlated with human cadaveric and xenogeneic bone, offering an alternative substrate with a similar biomechanical structure and consistent characteristics. Moreover, the use of an artificial substrate offers a uniform structural pattern and density that avoids several different variables, such as the temperature and environmental humidity. This material exhibits similar properties to bone, and it is reliable and requires no special handling or preservation. 


\subsection{Implant Preparation}

Sinus-PlantTM (Oralplant Suisse, Mendrisio, Switzerland) titanium implants (test implants) were used for the present in vitro investigation (Figure 1). The morphology of the implant provided a conometrical coupling by the troncoconical geometry, with a height of the conical section of $4 \mathrm{~mm}$. The $0.4 \mathrm{~mm}$ pitch profile of the threads generated a lateral bone condensation induced by a progressive expansion of the implant site and increased the primary stability during the placement. The round apex was studied to try to preserve the Schneiderian membrane and to create a controlled insertion pressure. The prosthetic platform provided a switching platform conometrical coupling allowing a better antibacterial seal. The Titanium Pull Spray Superficial (TPSS) obtained by a high-precision treatment of the implant with 0.5 -micron aluminium oxide tips provided rounded and porous surface microcavities.
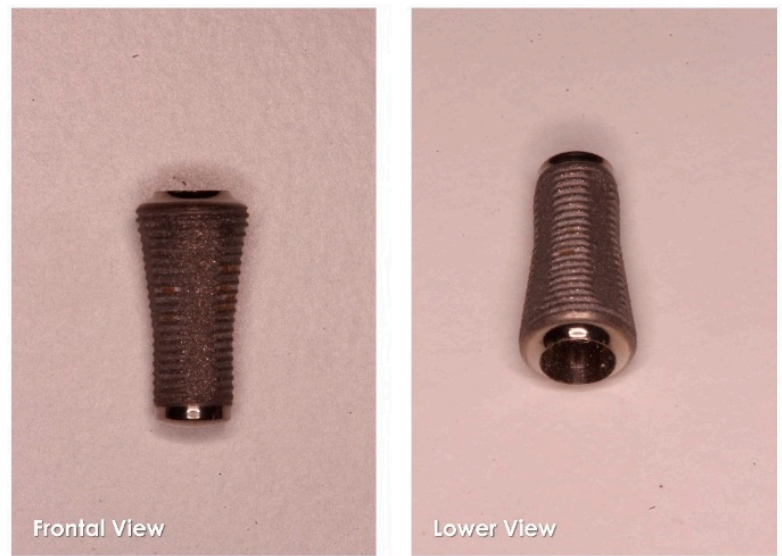

Figure 1. Sinus-Plant (Oralplant Suisse, Mendrisio, Switzerland). Test Implant.

A cylindrical screw-shaped implant was used as the control implant: $13 \mathrm{~mm}$ length diameter of the platform $4.1 \mathrm{~mm}$, and body diameter $3.75 \mathrm{~mm}$ (Restore, Keystone Dental, Burlington, MA, USA). The coronal portion of the two experimental implants presented the same diameter but a different shape: a troncoconical geometry for the test implant and a cylindrical morphology for the control implant (Figure 2).
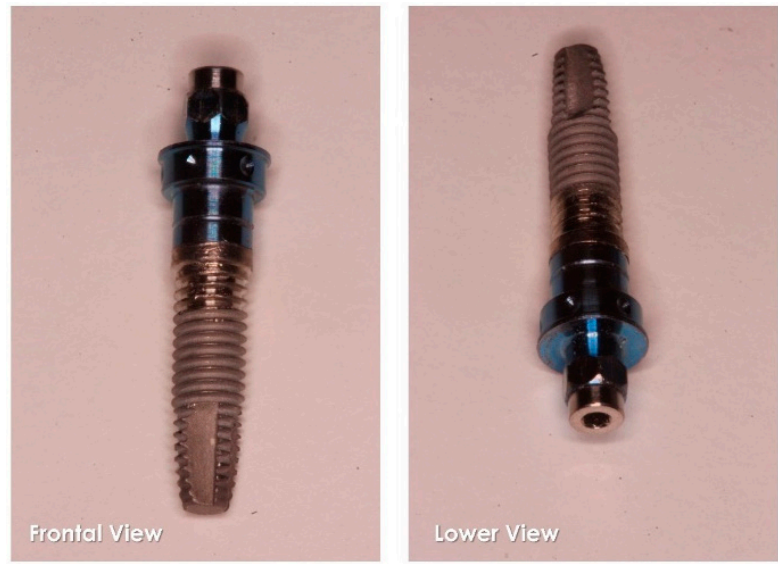

Figure 2. Restore (Keystone Dental, Burlington, MA, USA) Control Implant.

\subsection{Experimental Design of the Study}

The present investigation was performed following a previously described study model design by Comuzzi et al. [25].

The experimental implants were positioned in accordance with the protocol described by the manufacturer. The drilling sequence was implant lance drill, $2 \mathrm{~mm}$ drill (1600 rpm), 
and 3.8 final drill (800 rpm) (Figure 3). The handpiece was calibrated at a speed of 70 $\mathrm{rpm}$ and a torque of $30 \mathrm{Ncm}$. The measurement of the insertion torque was obtained and elaborated by the dedicated software package (ImpDat Plus, East Lansing, MI, USA) provided by a digital device. The insertion torque (IT, $\mathrm{Ncm}$ ) assessment indicated the maximum clockwise force recorded during the positioning in the implant site. The entire procedure was conducted by a single operator (LC), evaluating the IT and the pullout measurement of both the test and control implants positioned in the polyurethane blocks. The experiment was conducted on different densities of polyurethane blocks (SawBones $\mathrm{H}$, Pacific Research Laboratories Inc., Vashon, WA, USA). The selected polyurethane blocks densities were:

- 10 pounds per cubic foot (pcf);

- 20 pounds per cubic foot (pcf);

- 30 pounds per cubic foot (pcf).

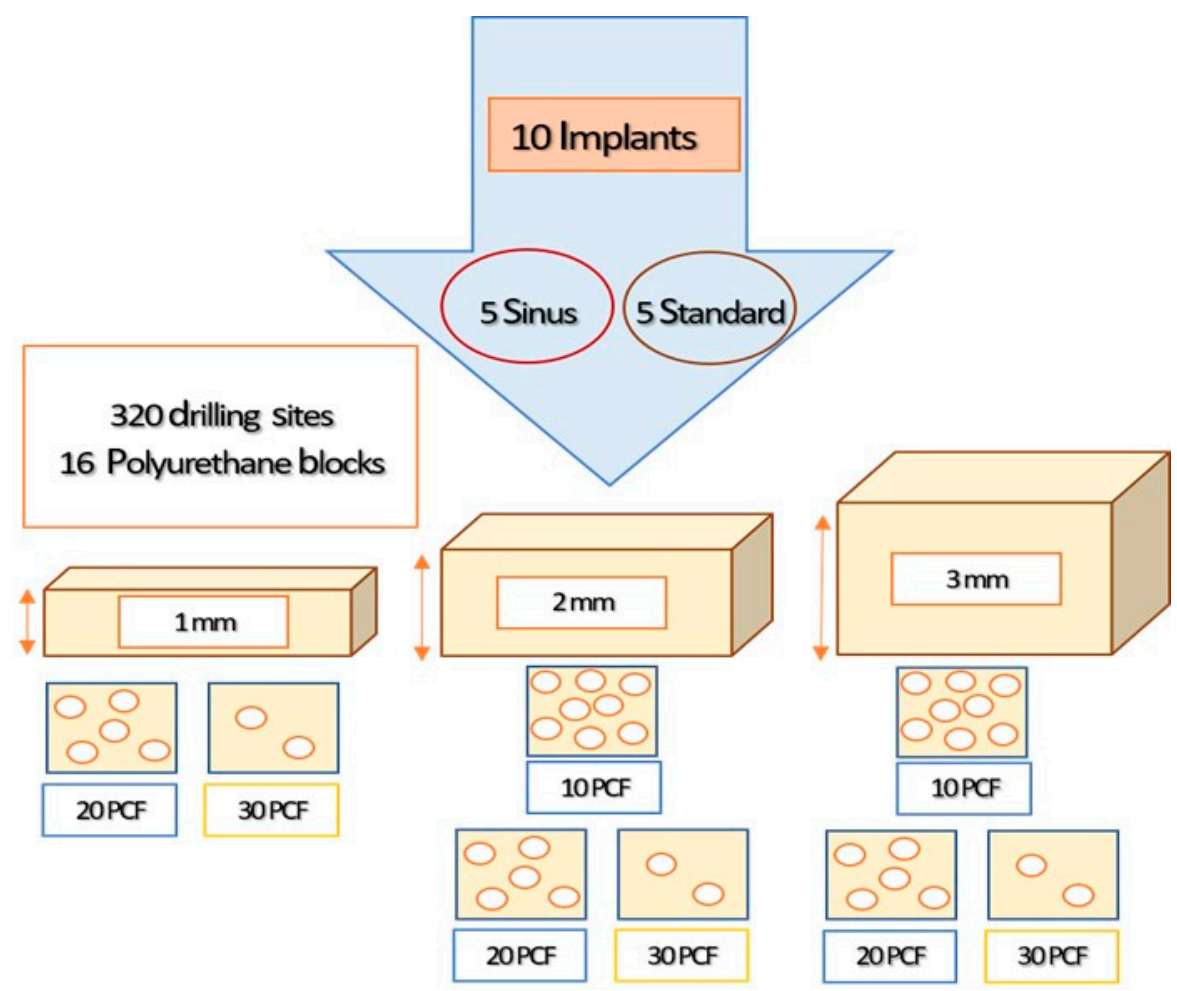

Figure 3. Summary of the study design. The test and control implant were tested in different polyurethane foams.

Moreover, 3 sizes of polyurethane substrates were used for a total of 16 blocks and 320 experimental sites:

- $\quad 13 \mathrm{~cm} \times 18 \mathrm{~cm} \times 1 \mathrm{~mm}(20,30 \mathrm{PCF})$;

- $13 \mathrm{~cm} \times 18 \mathrm{~cm} \times 2 \mathrm{~mm}(10,20,30 \mathrm{PCF})$;

- $13 \mathrm{~cm} \times 18 \mathrm{~cm} \times 3 \mathrm{~mm}(10,20,30 \mathrm{PCF})$.

\subsection{Implant Drill}

Test implants were positioned by a $2 \mathrm{~mm}$ surgical drill set at $1500 \mathrm{rpm}, 3.8 \mathrm{~mm}$ drill at $800 \mathrm{rpm}, 10 \mathrm{~mm}$ length drill, and $4.5 \mathrm{~mm}$ drill at $40 \mathrm{rpm}$. The implant fixture was positioned, imposing a predetermined maximum torque of $46 \mathrm{Ncm}$ at $30 \mathrm{rpm}$, using a surgical motor. The control group fixtures were positioned in accordance with the following drilling protocol: $2 \mathrm{~mm}$ drill at $1500 \mathrm{rpm}, 3 \mathrm{~mm}$ drill at $800 \mathrm{rpm}$. The control implant was positioned by a calibrated torque of $46 \mathrm{Ncm}$ at $30 \mathrm{rpm}$ using a surgical motor. 


\subsection{Insertion Torque E Pull-Out Torque}

The laboratory experiment was performed evaluating the IT and the PO peaks measured by an electronic torquemeter (UNIKA, Oralplant Suisse, Mendrisio, Switzerland). The implant IT and PO torque gauges were measured at the complete positioning in the polyurethane lamina. In the present investigation, 320 sites (160 for each group) in different polyurethane blocks were evaluated, 20 osteotomies for each density and polyurethane block size.

\subsection{Resonance Frequency Analysis}

The implant primary stability was measured in accordance with the resonance frequency analysis (RFA) that was assessed following the implant stability quotient score (ISQ). The experimental measurement was performed through a dedicated device Smart-Pegs (Osstell Mentor Device, Integration Diagnostic AB, Savadelen, Sweden) (Figures 4 and 5). The ISQ score range was classified into different stability classes [22]:

- Low stability < 60 ISQ;

- Medium stability 60-70 ISQ;

- $\quad$ High stability > 70 ISQ.

For each sample, the assessment was performed 2 times and the measurements were performed according to two difference orientations at 90-degree. The ISQ means were calculated and considered for the statistical analysis.

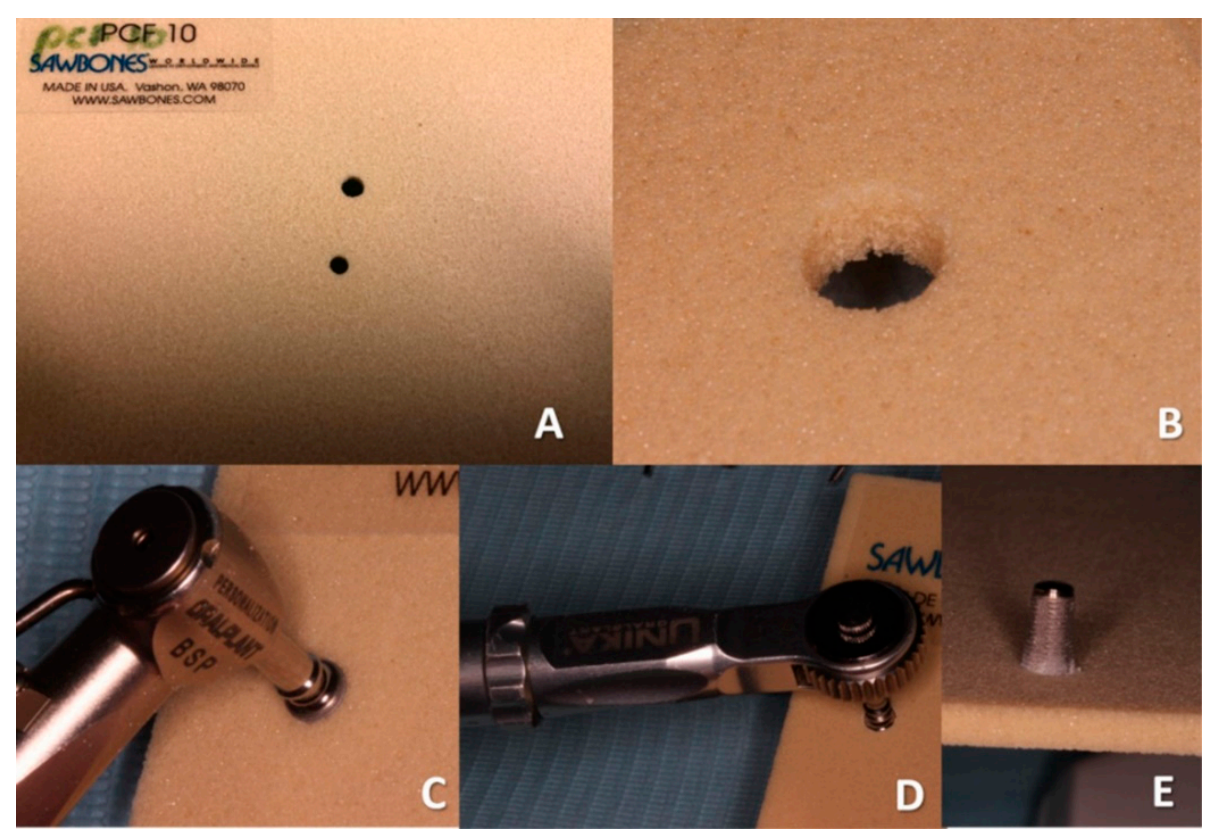

Figure 4. Test Group. (A) Polyurethane Block drilling holes. (B) Aspect of site preparation after drilling. (C) Placement of the Sinus Implant by the surgical motor at $1 \mathrm{~mm}$ from the block level. (D) Placement of the fixture for the last $1 \mathrm{~mm}$ with a manual ratchet. (E) Aspect of the backside of the preparation. 


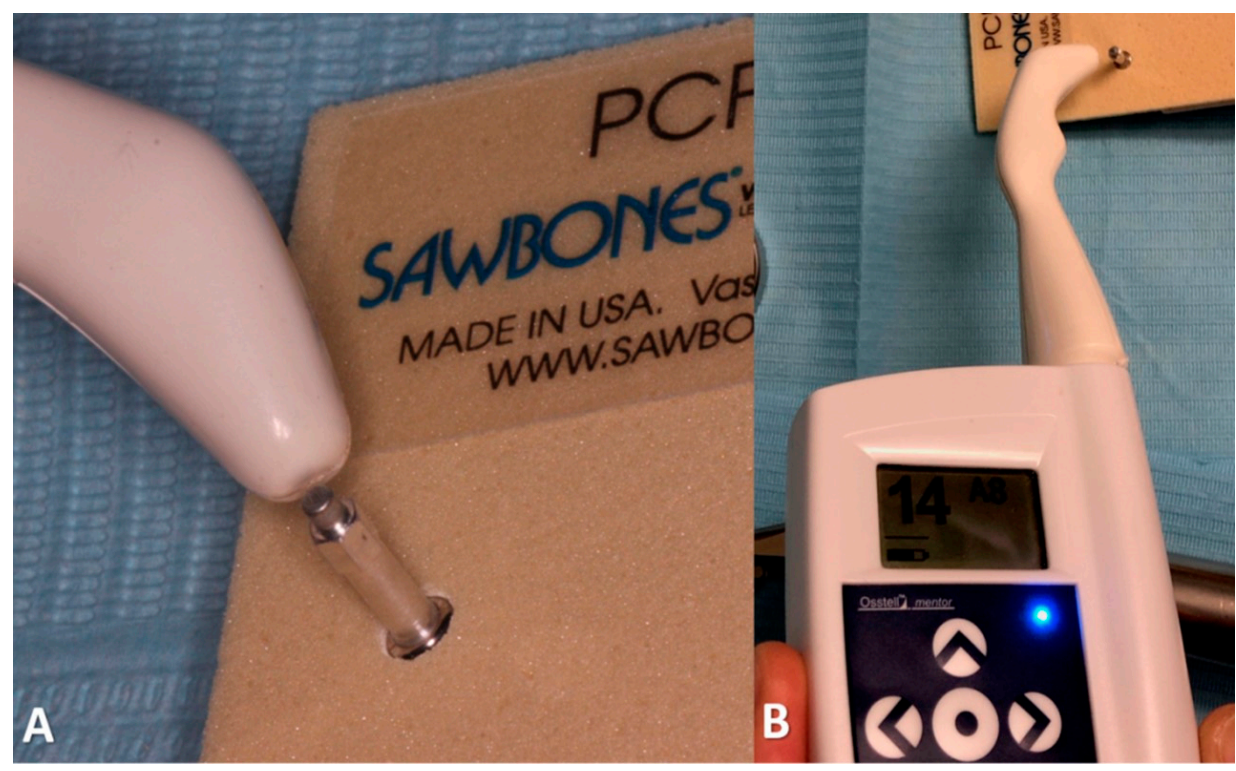

Figure 5. Control Group: RFA measurement of the implant positioned in the polyurethane block. The evaluation was repeated two times for each measurement. (A) Dental implant micromovement evaluation through the RFA implant stability. (B) Detail of the measurement of the implant stability quotient (ISQ).

\subsection{Statistical Analysis}

The IT, PO, and RFA means were evaluated for both the test and control groups. The study data were evaluated by the one-way ANOVA followed by Tukey post-hoc test. The statistical significance was set for $p$-value $<0.05$. The statistical analysis and descriptive statistics were performed by the Graphpad 6 (Prism, San Diego, CA, USA) software package. The operator agreement for RFA assessment was performed by the Bland-Altman plot and the linear regression model was adopted to determine the agreement of the RFA assessment.

\section{Results}

The study findings showed a significant difference of the IT values between both the test and control implant groups positioned in polyurethane substrates conditions $(p<0.01)$ (Figure 6). The IT of the test Implants showed a significant increase in higher bone densities.

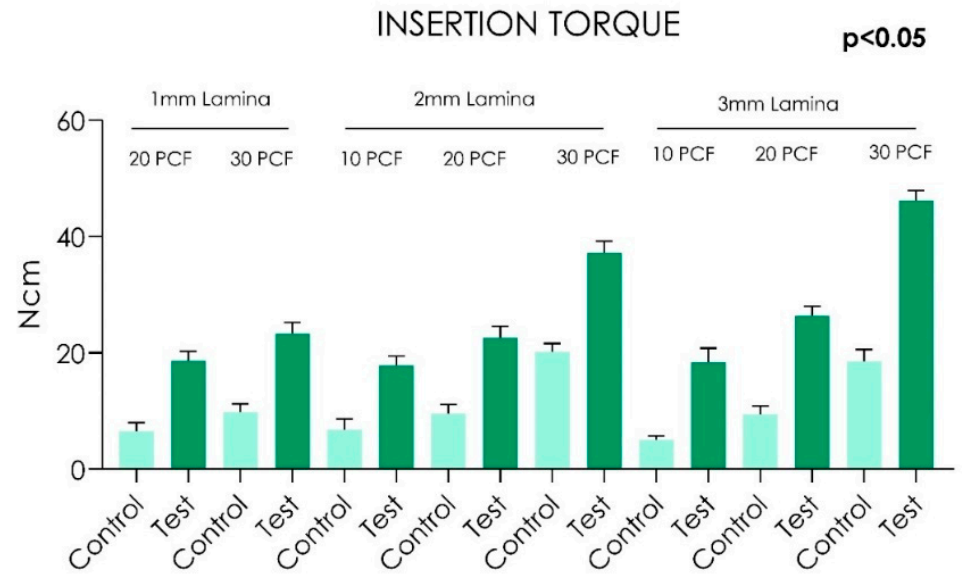

Figure 6. Insertion Torque Values for Test Implants and Control Implants in different polyurethane block conditions.

The dental implants of the control group did not show statistically significant differences of the insertion torque and pull out torque means when positioned in 1 and $2 \mathrm{~mm}$ 
bone thicknesses (10 and 20 PCF) blocks ( $p>0.05)$. A significant increase of IT and PO was reported with the implant positioned in $2 \mathrm{~mm} / 30$ PCF lamina and $3 \mathrm{~mm} / 30$ PCF lamina $(p<0.01)$. In both groups, the insertion torque values were higher than the pull-out torque values $(p<0.01)$ (Figures 6 and 7) (Tables 1 and 2).

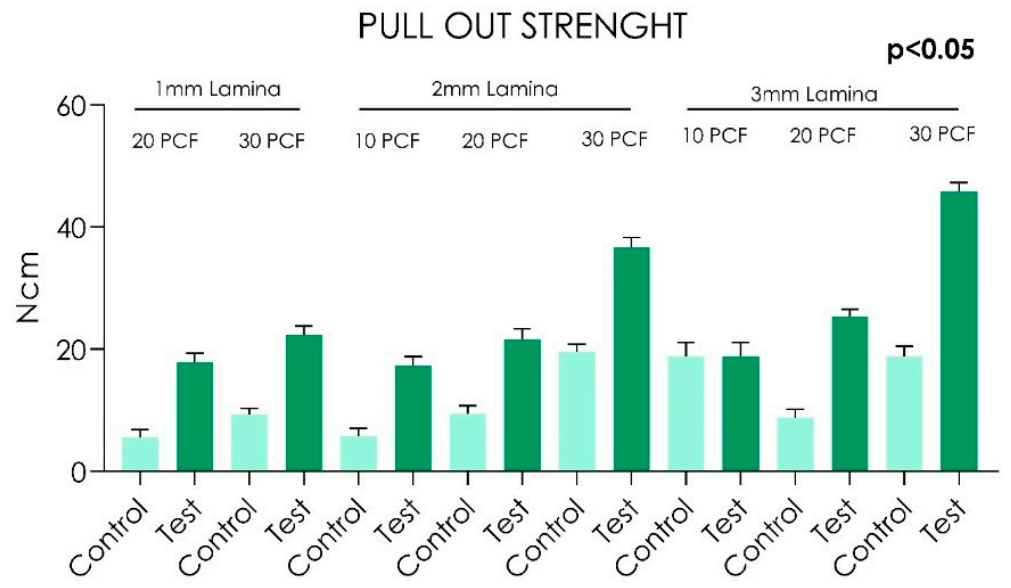

Figure 7. Evaluation for Test Implants and Control Implants in different polyurethane block conditions.

Table 1. Control Implant and Test Implant Insertion Torque values measured in different experimental conditions. CI = Control Implant; TI = Test Implant.

\begin{tabular}{|c|c|c|c|c|c|c|c|c|c|c|c|c|c|c|c|c|}
\hline & \multicolumn{4}{|c|}{1 MM Polyurethane } & \multicolumn{6}{|c|}{2 MM Polyurethane } & \multicolumn{6}{|c|}{3 MM Polyurethane } \\
\hline & \multicolumn{2}{|c|}{20 PCF } & \multicolumn{2}{|c|}{30 PCF } & \multicolumn{2}{|c|}{10 PCF } & \multicolumn{2}{|c|}{20 PCF } & \multicolumn{2}{|c|}{30 PCF } & \multicolumn{2}{|c|}{10 PCF } & \multicolumn{2}{|c|}{$20 \mathrm{PCF}$} & \multicolumn{2}{|c|}{30 PCF } \\
\hline & Control & Test & Control & Test & Control & Test & Control & Test & Control & Test & Control & Test & Control & Test & Control & Test \\
\hline Min & 5 & 15 & 8 & 20 & 5 & 15 & 8 & 20 & 18 & 35 & 4 & 12 & 6 & 23 & 15 & 43 \\
\hline $\operatorname{Max}$ & 8 & 20 & 12 & 25 & 10 & 20 & 12 & 25 & 22 & 40 & 6 & 22 & 12 & 28 & 22 & 48 \\
\hline Range & 3 & 5 & 4 & 5 & 5 & 5 & 4 & 5 & 4 & 5 & 2 & 10 & 6 & 5 & 7 & 5 \\
\hline Mean & 6.5 & 18.7 & 9.8 & 23.3 & 6.85 & 17.8 & 9.6 & 22.55 & 20.2 & 37.2 & 5.05 & 18.4 & 9.4 & 26.4 & 18.55 & 46.2 \\
\hline $\begin{array}{l}\text { Std } \\
( \pm)\end{array}$ & 1.53 & 1.59 & 1.43 & 1.92 & 1.81 & 1.67 & 1.53 & 2.0 & 1.43 & 1.98 & 0.68 & 2.45 & 1.46 & 1.63 & 2.0 & 1.70 \\
\hline
\end{tabular}

Table 2. Pull Out Strength values of Control Implants and Test Implants. CI = Control Implant; $\mathrm{TI}=$ Test Implant.

\begin{tabular}{|c|c|c|c|c|c|c|c|c|c|c|c|c|c|c|c|c|}
\hline & \multicolumn{4}{|c|}{1 MM Polyurethane } & \multicolumn{6}{|c|}{2 MM Polyurethane } & \multicolumn{6}{|c|}{3 MM Polyurethane } \\
\hline & \multicolumn{2}{|c|}{20 PCF } & \multicolumn{2}{|c|}{30 PCF } & \multicolumn{2}{|c|}{10 PCF } & \multicolumn{2}{|c|}{20 PCF } & \multicolumn{2}{|c|}{30 PCF } & \multicolumn{2}{|c|}{10 PCF } & \multicolumn{2}{|c|}{20 PCF } & \multicolumn{2}{|c|}{30 PCF } \\
\hline & Control & Test & Control & Test & Control & Test & Control & Test & Control & Test & Control & Test & Control & Test & Control & Test \\
\hline Min & 5 & 15 & 8 & 20 & 5 & 15 & 8 & 20 & 18 & 35 & 15 & 15 & 6 & 23 & 15 & 43 \\
\hline Max & 8 & 20 & 10 & 25 & 8 & 20 & 12 & 25 & 22 & 40 & 22 & 22 & 10 & 28 & 22 & 48 \\
\hline Range & 3 & 5 & 2 & 5 & 3 & 5 & 4 & 5 & 4 & 5 & 7 & 7 & 4 & 5 & 7 & 5 \\
\hline Mean & 5.6 & 17.9 & 9.3 & 22.3 & 5.75 & 17.3 & 9.4 & 21.6 & 19.6 & 36.6 & 18.9 & 18.9 & 8.8 & 25.4 & 18.8 & 45.8 \\
\hline $\begin{array}{l}\text { Std } \\
( \pm)\end{array}$ & 1.23 & 1.50 & 0.97 & 1.46 & 1.33 & 1.45 & 1.31 & 1.72 & 1.23 & 1.69 & 2.16 & 2.16 & 1.36 & 1.14 & 1.73 & 1.50 \\
\hline
\end{tabular}

As for the RFA analyses (Figure 8), the measurements were compared following the linear regression scatter plot and the Bland-Altman model (Figures 8-10). The Pearson correlation coefficient was 0.98 (95\% CI 4.08 to 4.68$)$ and the agreement analysis showed that the mean difference between measurements was -0.30 . The Bland-Altman plot showed the differences between the RFA measurements and their limits of agreement (Figure 9). Intergroup RFA measurement showed the highest values in the test Implants when compared to the control implants in all experimental densities and block thicknessed $(p<0.01)$ (Figure 8). Intragroup evaluation of the test implants showed an increase of the ISQ values related to the increase of the block thicknesses and densities in all conditions $(p<0.01)$. Control implants showed lower values of ISQ at $2 \mathrm{~mm} 10 \mathrm{PCF}$, with a significant increase at higher bone densities $(p<0.05)$ (Figure 9). 


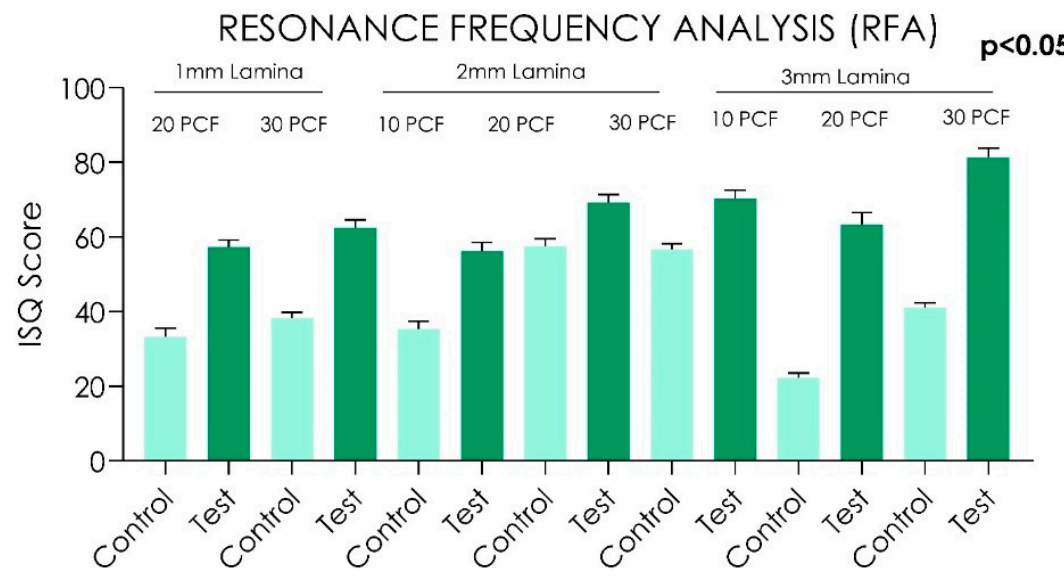

Figure 8. RFA values for Test Implants and Control Implants in different experimental conditions.

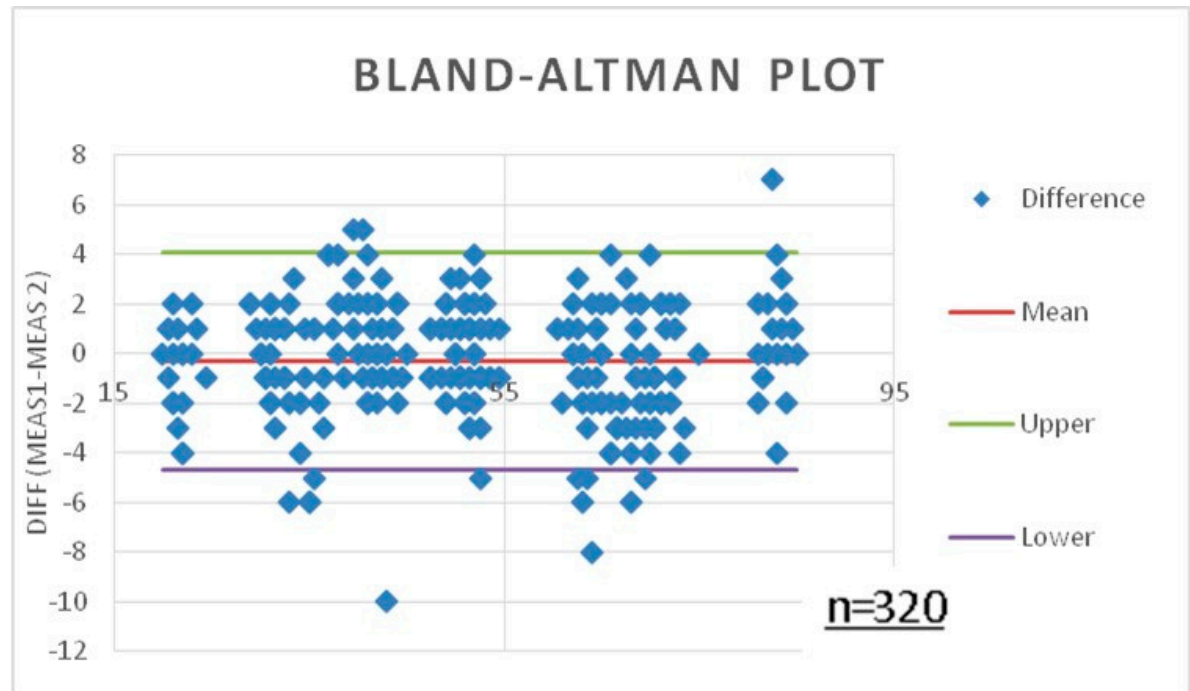

Figure 9. Bland-Altman Plot about the agreement of ISQ measurement for each sample. The mean difference was estimated bias, and the SD of the differences measured the random fluctuations around this mean.

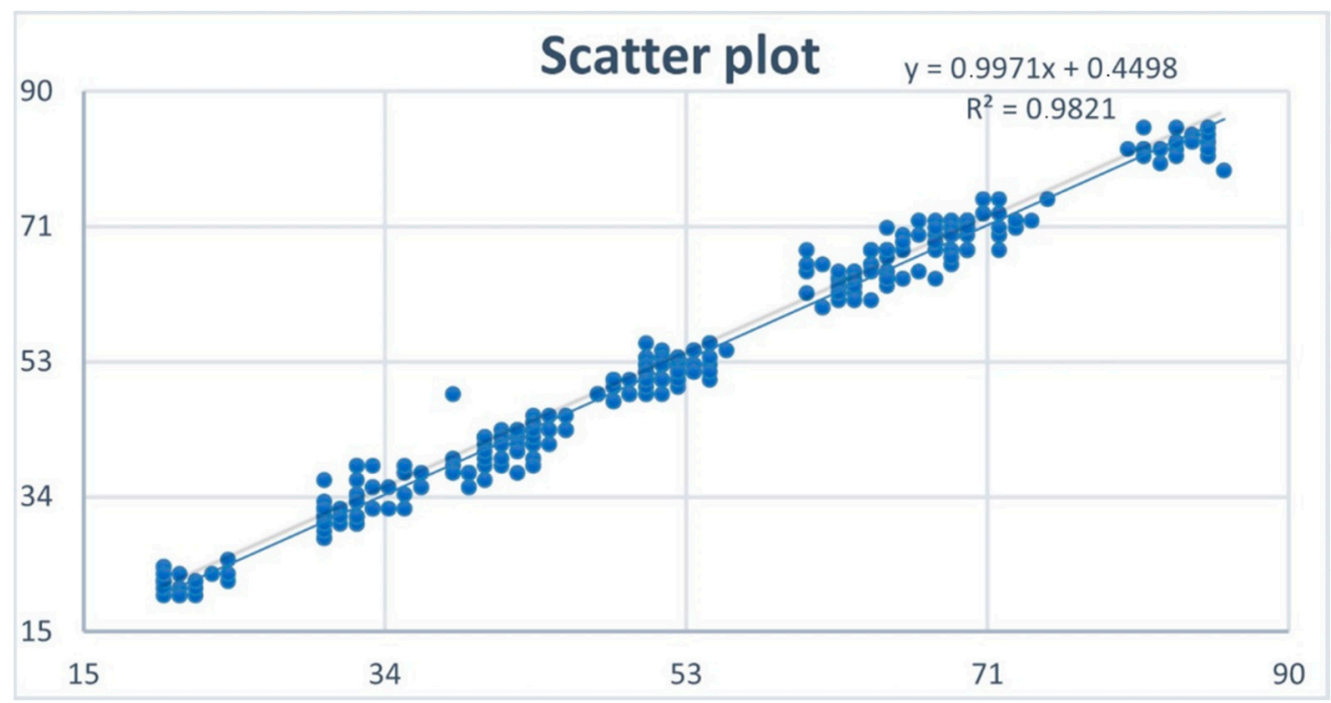

Figure 10. Scatter Plot about the agreement of ISQ measurement for each sample showing the variability of the repeated measurements. 


\section{Discussion}

Polyurethane material in the form of solid rigid blocks and foams has been considered a useful bone substitute for biomechanical laboratory research as early as the 1990s to test materials and implantable medical devices [24]. Commercially, the samples are available in the form of homogeneous blocks or polyurethane composites-glass fibre epoxy resin, in order to mimic the human cortical bone behaviour and a cellular internal structure to simulate the cancellous alveolar bone ridges [26,27]. The rationale of the present investigation was to recreate in a laboratory standardized simulation of a particular recurrent clinical condition of severe bone atrophy with a bone ridge height $<3 \mathrm{~mm}$. On the contrary, the limit of the present study was associated with the possible microscopic mismatch that could also be present in a calibrated drilling protocol. In the second instance, the present study aimed to evaluate the reliability of the surgical procedure performed on an artificial bone substrate measuring the primary stability and the micromovement response with an intra-operator agreement approach. As reported by the mechanostatic theory by Frost [28], this evidence is recurrent in the edentulous jaws area with an overloading generated by a passive prosthetic function that is able to generate severe bone resorption that could invalidate an efficient implant-supported rehabilitation in maxillary atrophic areas [29-33]. In this way, the different experimental conditions considered a wide density pool in order to evaluate the behaviour and the mechanical response of the tested implants in a very critical clinical occurrence, while the most frequent intra-operative complication in this region during the implant positioning is the early loss of fixture stability [34,35].

The primary stability is described as the mechanical frictional stability of the implant device when positioned in native bone tissue [36]. Moreover, the achievement of primary stability in the posterior maxilla represents a critical factor due to the poor bone density of this anatomical region, especially for an immediate functional loading protocol [12]. Primary implant stability seems to be strictly correlated to implant diameter and length, the micro- and macro-design of the threads, the cortical thickness, and the cortical bone density $[5,15]$. The maximum peak torque recorded during the implant fixture positioning was provided by the rotational stability of the implant. The implant primary stability could be clinically assessed in accordance with different quantitative and semi-quantitative methods, such as insertion torque [37], removal torque [16], periotest [38], and resonance frequency analysis $[10,22]$. In the present investigation, the test and control implant placement stability was assessed on a synthetic artificial substrate in the form of standardized rigid polyurethane foam blocks.

In the present study, the control implant group showed the lowest values of insertion and pull-out torque in all experimental conditions. The control implant group showed, moreover, ISQ values lower than 60, with a low stability of the implant [39]. On the contrary, the test implants showed significantly higher values of insertion torque, pull-out torque, and ISQ in all experimental conditions.

Clinically, a minimum of $15 \mathrm{~N} / \mathrm{cm}$ torque and 65 ISQ has been recommended for a successful implant osseointegration, with higher values related to an increased percentage of success rates [37]. Additionally, a maximum torque of $50 \mathrm{~N} / \mathrm{cm}$ has been recommended to preserve the native bone tissue against mechanical stress, which could potentially generate peri-implant bone loss [40]. The two implants used in this study had a different morphology and outer diameter. The conometrical geometry of the implant seemed to provide an important and relevant effect on implant stability.

The inverse conical geometry of the implant is advantageous in many different clinical occurrences and in low-density bone [25,41]. In fact, the posterior maxilla regions are generally associated with a reduced cortical compartment and wider cancellous/medullary spaces [42]. Moreover, the pneumatization of the maxillary sinus is clinically associated in edentulous posterior maxillary regions with bone augmentation procedures [43].

The effectiveness of the present study showed an excellent primary stability of the test implants in the area of the atrophic distal maxilla, while the results speak in favour 
of the use of very well mineralized bone, such as palatal bone and pterygoid plates of the sphenoid bone, used in anchoring tubero-pterygoid implants $[33,44-50]$.

The sinus augmentation procedures are generally oriented in relation to the vertical residual bone tissue with a two-stage/single stage surgery [51,52]. The capacity of a successful primary stability with a $2-3 \mathrm{~mm}$ residual bone takes advantage of a strong reduction of the rehabilitation period, less surgical interventions, and a cost-effective procedures [53]. Moreover, in case of D4 bone, this geometry could be used to increase the primary stability and determine an effective increase of the insertion torque parameters during the surgical procedure [11]. The design of the test implant, with its self-condensing properties on the implant preparation walls, could produce an increase of the friction between the implant and material. In fact, micromovement or motion between freshly placed implant and bone can jeopardize the osseointegration in vivo [40,54-57]. This aspect could be a determinant factor in the posterior maxilla, where there is a reduced bone volume and poor density. Obtaining primary stability in such an area is critical for successful implant therapy [15]. Structural and morphological alterations related to edentulism in the posterior maxilla often require bone augmentation procedures for implant-supported restoration [58-65]. The residual bone height represents a determinant for the clinician in order to choose a one- or two-stage approach for implant placement [1,66-68].

\section{Conclusions}

The effectiveness of the present study showed that the dental implant self-condensing design seems advantageous for the treatment of maxillary severe atrophies due to the higher stability obtained in all experimental conditions and densities. This evidence could represent a useful tool for a one-stage surgical approach in the presence of limited residual native bone as an alternative to a delayed approach in bone regeneration protocols.

Author Contributions: Conceptualization, L.C. and M.T.; methodology, L.C. and N.D.P.; software, P.B.; validation, A.L., P.B. and C.D.; formal analysis, A.P. and N.D.P.; investigation, G.I.; resources, A.L.; data curation, G.I. and C.D.; writing-original draft preparation, M.T.; writing-review and editing, L.C.; visualization, P.B.; supervision, L.C. and N.D.P.; project administration, G.I.; funding acquisition, A.L. All authors have read and agreed to the published version of the manuscript.

Funding: The authors declared that this study has not received funding.

Institutional Review Board Statement: This article does not contain any studies with human participants or animals performed by any of the authors.

Informed Consent Statement: Not applicable.

Data Availability Statement: All experimental data to support the findings of this study are available contacting the corresponding author upon request.

Conflicts of Interest: The authors declare no conflict of interest.

\section{References}

1. Albrektsson, T.; Chrcanovic, B.; Östman, P.-O.; Sennerby, L. Initial and Long-Term Crestal Bone Responses to Modern Dental Implants. Periodontol. 2000 2017, 73, 41-50. [CrossRef]

2. Fujiwara, S.; Kato, S.; Bengazi, F.; Velez, J.U.; Tumedei, M.; Kotsu, M.; Botticelli, D. Healing at Implants Installed in Osteotomies Prepared Either with a Piezoelectric Device or Drills: An Experimental Study in Dogs. Oral Maxillofac. Surg. 2020, 25, 65-73. [CrossRef] [PubMed]

3. Kotsu, M.; Velez, J.U.; Bengazi, F.; Tumedei, M.; Fujiwara, S.; Kato, S.; Botticelli, D. Healing at implants installed from 70- to $<10-N c m$ insertion torques: An experimental study in dogs. Oral Maxillofac. Surg. 2020, 25, 55-64. [CrossRef] [PubMed]

4. Javed, F.; Al-Hezaimi, K.; Almas, K.; Romanos, G.E. Is Titanium Sensitivity Associated with Allergic Reactions in Patients with Dental Implants? A Systematic Review. Clin. Implant Dent. Relat. Res. 2013, 15, 47-52. [CrossRef]

5. Elias, C.N.; Rocha, F.A.; Nascimento, A.L.; Coelho, P.G. Influence of Implant Shape, Surface Morphology, Surgical Technique and Bone Quality on the Primary Stability of Dental Implants. J. Mech. Behav. Biomed. Mater. 2012, 16, 169-180. [CrossRef] [PubMed]

6. Gehrke, S.A.; Tumedei, M.; Aramburú Júnior, J.; Treichel, T.L.E.; Kolerman, R.; Lepore, S.; Piattelli, A.; Iezzi, G. Histological and Histomorphometrical Evaluation of a New Implant Macrogeometry. A Sheep Study. Int. J. Environ. Res. Public Health 2020, 17, 3477. [CrossRef] 
7. Hayek, E.; Aoun, G.; Geha, H.; Nasseh, I. Image-Based Bone Density Classification Using Fractal Dimensions and Histological Analysis of Implant Recipient Site. Acta Inform. Med. 2020, 28, 272-277. [CrossRef]

8. De Andrade, C.L.; Carvalho, M.A.; Bordin, D.; Da Silva, W.J.; Cury, A.D.B.; Sotto-Maior, B. Biomechanical Behavior of the Dental Implant Macrodesign. Int. J. Oral Maxillofac. Implants 2017, 32, 264-270. [CrossRef]

9. Kuroshima, S.; Kaku, M.; Ishimoto, T.; Sasaki, M.; Nakano, T.; Sawase, T. A Paradigm Shift for Bone Quality in Dentistry: A Literature Review. J. Prosthodont. Res. 2017, 61, 353-362. [CrossRef]

10. Scarano, A.; Carinci, F.; Quaranta, A.; Iezzi, G.; Piattelli, M.; Piattelli, A. Correlation between Implant Stability Quotient (ISQ) with Clinical and Histological Aspects of Dental Implants Removed for Mobility. Int. J. Immunopathol. Pharmacol. 2007, 20, 33-36. [CrossRef]

11. Shadid, R.M.; Sadaqah, N.R.; Othman, S.A. Does the Implant Surgical Technique Affect the Primary and/or Secondary Stability of Dental Implants? A Systematic Review. Int. J. Dent. 2014, 2014, 204838. [CrossRef]

12. Pommer, B.; Hof, M.; Fädler, A.; Gahleitner, A.; Watzek, G.; Watzak, G. Primary Implant Stability in the Atrophic Sinus Floor of Human Cadaver Maxillae: Impact of Residual Ridge Height, Bone Density, and Implant Diameter. Clin. Oral Implants Res. 2014, 25, e109-e113. [CrossRef] [PubMed]

13. Kokubo, T. Design of Bioactive Bone Substitutes Based on Biomineralization Process. Mater. Sci. Eng. C 2005, 25, 97-104. [CrossRef]

14. Degidi, M.; Daprile, G.; Piattelli, A. Influence of Underpreparation on Primary Stability of Implants Inserted in Poor Quality Bone Sites: An in Vitro Study. J. Oral Maxillofac. Surg. 2015, 73, 1084-1088. [CrossRef] [PubMed]

15. Falco, A.; Berardini, M.; Trisi, P. Correlation Between Implant Geometry, Implant Surface, Insertion Torque, and Primary Stability: In Vitro Biomechanical Analysis. Int. J. Oral Maxillofac. Implants 2018, 33, 824-830. [CrossRef] [PubMed]

16. Scarano, A.; Carinci, F.; Mangano, C.; Quaranta, A.; Piattelli, A. Removal Torque Values of Titanium Implants Inserted into Bone Defects Filled with Hydroxyapatite: A Histologic and Histomorphometric Analysis in Rabbit. Int. J. Immunopathol. Pharmacol. 2007, 20, 49-53. [CrossRef]

17. Gehrke, S.A.; Mazón, P.; Del Fabbro, M.; Tumedei, M.; Aramburú Júnior, J.; Pérez-Díaz, L.; de Aza, P.N. Histological and Histomorphometric Analyses of Two Bovine Bone Blocks Implanted in Rabbit Calvaria. Symmetry 2019, 11, 641. [CrossRef]

18. Tumedei, M.; Piattelli, A.; Degidi, M.; Mangano, C.; Iezzi, G. A Narrative Review of the Histological and Histomorphometrical Evaluation of the Peri-Implant Bone in Loaded and Unloaded Dental Implants. A 30-Year Experience (1988-2018). Int. J. Environ. Res. Public Health 2020, 17, 2088. [CrossRef]

19. Tumedei, M.; Piattelli, A.; Degidi, M.; Mangano, C.; Iezzi, G. A 30-Year (1988-2018) Retrospective Microscopical Evaluation of Dental Implants Retrieved for Different Causes: A Narrative Review. Int. J. Periodontics Restor. Dent. 2020, 40, e211-e227. [CrossRef]

20. Fanali, S.; Tumedei, M.; Pignatelli, P.; Inchingolo, F.; Pennacchietti, P.; Pace, G.; Piattelli, A. Implant Primary Stability with an Osteocondensation Drilling Protocol in Different Density Polyurethane Blocks. Comput. Methods Biomech. Biomed. Eng. 2020, 24, 14-20. [CrossRef]

21. Cordioli, G.; Majzoub, Z.; Piattelli, A.; Scarano, A. Removal Torque and Histomorphometric Investigation of 4 Different Titanium Surfaces: An Experimental Study in the Rabbit Tibia. Int. J. Oral Maxillofac. Implants 2000, 15, 668-674.

22. Fu, M.-W.; Fu, E.; Lin, F.-G.; Chang, W.-J.; Hsieh, Y.-D.; Shen, E.-C. Correlation Between Resonance Frequency Analysis and Bone Quality Assessments at Dental Implant Recipient Sites. Int. J. Oral Maxillofac. Implants 2017, 32, 180-187. [CrossRef] [PubMed]

23. Kim, D.-G.; Kwon, H.-J.; Jeong, Y.-H.; Chien, H.-H.; Crance, S.; Agnew, A.M.; Battula, S.; Lee, J.W.; Wen, H.B. Associations of Resonance Frequency Analysis with Dynamic Mechanical Analysis of Dental Implant Systems. Clin. Implant Dent. Relat. Res. 2016, 18, 332-341. [CrossRef] [PubMed]

24. ASTM. 01: Standard Specification for Rigid Polyurethane Foam for Use as a Standard Material for Testing Orthopedic Devices and Instruments; ASTM: West Conshohcken, PA, USA, 1839.

25. Comuzzi, L.; Iezzi, G.; Piattelli, A.; Tumedei, M. An In Vitro Evaluation, on Polyurethane Foam Sheets, of the Insertion Torque (IT) Values, Pull-Out Torque Values, and Resonance Frequency Analysis (RFA) of NanoShort Dental Implants. Polymers 2019, 11, 1020. [CrossRef]

26. Moretti Neto, R.T.; Hiramatsu, D.A.; Suedam, V.; Conti, P.C.R.; Rubo, J.H. Validation of an Experimental Polyurethane Model for Biomechanical Studies on Implant-Supported Prosthesis-Compression Tests. J. Appl. Oral Sci. Rev. FOB 2011, $19,47-51$. [CrossRef]

27. Miyashiro, M.; Suedam, V.; Moretti Neto, R.T.; Ferreira, P.M.; Rubo, J.H. Validation of an Experimental Polyurethane Model for Biomechanical Studies on Implant Supported Prosthesis-Tension Tests. J. Appl. Oral Sci. Rev. FOB 2011, 19, 244-248. [CrossRef]

28. Frost, H.M. Bone's Mechanostat: A 2003 Update. Anat. Rec. A Discov. Mol. Cell. Evol. Biol. 2003, 275, 1081-1101. [CrossRef]

29. Scarano, A.; Noumbissi, S.; Gupta, S.; Inchingolo, F.; Stilla, P.; Lorusso, F. Scanning Electron Microscopy Analysis and Energy Dispersion X-ray Microanalysis to Evaluate the Effects of Decontamination Chemicals and Heat Sterilization on Implant Surgical Drills: Zirconia vs. Steel. Appl. Sci. 2019, 9, 2837. [CrossRef]

30. Dias, F.J.d.N.; Pecorari, V.G.A.; Martins, C.B.; Del Fabbro, M.; Casati, M.Z. Short Implants versus Bone Augmentation in Combination with Standard-Length Implants in Posterior Atrophic Partially Edentulous Mandibles: Systematic Review and Meta-Analysis with the Bayesian Approach. Int. J. Oral Maxillofac. Surg. 2019, 48, 90-96. [CrossRef] 
31. Bertossi, D.; Nocini, R.; Luciano, U.; Galzignato, P.F.; Ricciardi, G.; Lucchese, A.; Tacchino, U.; Donadello, D.; Lanaro, L.; Gualdi, A.; et al. Piezoelectric surgery inserts vs conventional burst: A clinical investigation. J. Biol. Regul. Homeost. Agents 2018, 32 (Suppl. 2), 15-19. [PubMed]

32. Scarano, A.; Mortellaro, C.; Brucoli, M.; Lucchina, A.G.; Assenza, B.; Lorusso, F. Short Implants: Analysis of 69 Implants Loaded in Mandible Compared With Longer Implants. J. Craniofacial Surg. 2018, 29, 2272-2276. [CrossRef]

33. Lorusso, F.; Conte, R.; Inchingolo, F.; Festa, F.; Scarano, A. Survival Rate of Zygomatic Implants for Fixed Oral Maxillary Rehabilitations: A Systematic Review and Meta-Analysis Comparing Outcomes between Zygomatic and Regular Implants. Dent. J. 2021, 9, 38. [CrossRef]

34. Carr, A.B.; Arwani, N.; Lohse, C.M.; Gonzalez, R.L.V.; Muller, O.M.; Salinas, T.J. Early Implant Failure Associated With Patient Factors, Surgical Manipulations, and Systemic Conditions. J. Prosthodont. 2019, 28, 623-633. [CrossRef]

35. Bornstein, M.M.; Halbritter, S.; Harnisch, H.; Weber, H.-P.; Buser, D. A Retrospective Analysis of Patients Referred for Implant Placement to a Specialty Clinic: Indications, Surgical Procedures, and Early Failures. Int. J. Oral Maxillofac. Implants 2008, 23, 1109-1116.

36. Al-Hezaimi, K.; Iezzi, G.; Rudek, I.; Al-Daafas, A.; Al-Hamdan, K.; Al-Rasheed, A.; Javed, F.; Piattelli, A.; Wang, H.-L. Histomorphometric Analysis of Bone Regeneration Using a Dual Layer of Membranes (DPTFE Placed over Collagen) in Fresh Extraction Sites: A Canine Model. J. Oral Implantol. 2015, 41, 188-195. [CrossRef] [PubMed]

37. Verrastro Neto, A.; Andrade, R.; Corrêa, M.G.; Casarin, R.C.V.; Casati, M.Z.; Pimentel, S.P.; Ribeiro, F.V.; Cirano, F.R. The Impact of Different Torques for the Insertion of Immediately Loaded Implants on the Peri-Implant Levels of Angiogenesis- and Bone-Related Markers. Int. J. Oral Maxillofac. Surg. 2018, 47, 651-657. [CrossRef] [PubMed]

38. Jeong, M.-A.; Jung, M.-K.; Kim, S.-G.; Oh, J.-S. Implant Stability Measurements in the Long-Term Follow-up of Dentis Implants: A Retrospective Study With Periotest. Implant Dent. 2015, 24, 263-266. [CrossRef]

39. Kokovic, V.; Jung, R.; Feloutzis, A.; Todorovic, V.S.; Jurisic, M.; Hämmerle, C.H.F. Immediate vs. Early Loading of SLA Implants in the Posterior Mandible: 5-Year Results of Randomized Controlled Clinical Trial. Clin. Oral Implants Res. 2014, 25, e114-e119. [CrossRef] [PubMed]

40. Goswami, M.M.; Kumar, M.; Vats, A.; Bansal, A.S. Evaluation of Dental Implant Insertion Torque Using a Manual Ratchet. Med. J. Armed Forces India 2015, 71, S327-S332. [CrossRef]

41. Tumedei, M.; Piattelli, A.; Falco, A.; de Angelis, F.; Lorusso, F.; Di Carmine, M.; Iezzi, G. An in Vitro Evaluation on Polyurethane Foam Sheets of the Insertion Torque, Removal Torque Values, and Resonance Frequency Analysis (RFA) of a Self-Tapping Threads and Round Apex Implant. Cell. Polym. 2020, 40, 20-30. [CrossRef]

42. Staedt, H.; Palarie, V.; Staedt, A.; Wolf, J.M.; Lehmann, K.M.; Ottl, P.; Kämmerer, P.W. Primary Stability of Cylindrical and Conical Dental Implants in Relation to Insertion Torque-A Comparative Ex Vivo Evaluation. Implant Dent. 2017, 26, 250-255. [CrossRef]

43. Del Fabbro, M.; Testori, T.; Francetti, L.; Weinstein, R. Systematic Review of Survival Rates for Implants Placed in the Grafted Maxillary Sinus. J. Prosthet. Dent. 2005, 94, 266. [CrossRef]

44. Lerario, F.; Roncati, M.; Gariffo, A.; Atorresi, E.; Lucchese, A.; Galanakis, A.; Palaia, G.; Romeo, U. Non-surgical periodontal treatment of peri-implant diseases with the adjunctive use of diode laser: Preliminary clinical study. Laser Med. Sci. 2016, 31, 1-6. [CrossRef]

45. Balaji, V.R.; Lambodharan, R.; Manikandan, D.; Deenadayalan, S. Pterygoid Implant for Atrophic Posterior Maxilla. J. Pharm. Bioallied Sci. 2017, 9, S261-S263. [CrossRef] [PubMed]

46. Ahlgren, F.; Størksen, K.; Tornes, K. A Study of 25 Zygomatic Dental Implants with 11 to 49 Months' Follow-up after Loading. Int J. Oral Maxillofac. Implants 2006, 21, 421-425.

47. Chrcanovic, B.R.; Albrektsson, T.; Wennerberg, A. Survival and Complications of Zygomatic Implants: An Updated Systematic Review. J. Oral Maxillofac. Surg. 2016, 74, 1949-1964. [CrossRef] [PubMed]

48. Akay, C.; Yaluğ, S. Biomechanical 3-Dimensional Finite Element Analysis of Obturator Protheses Retained with Zygomatic and Dental Implants in Maxillary Defects. Med. Sci. Monit. 2015, 21, 604-611. [CrossRef] [PubMed]

49. Mavriqi, L.; Lorusso, F.; Conte, R.; Rapone, B.; Scarano, A. Zygomatic Implant Penetration to the Central Portion of Orbit: A Case Report. BMC Ophthalmol. 2021, 21, 121. [CrossRef] [PubMed]

50. Scarano, A.; Conte, R.; Murmura, G.; Lorusso, F.; Harrath, A.H. Satisfaction Grade Assessment of Patients Treated with Zygomatic Implants with Self-Tapping Apex and Machined Body. J. Biol. Regul. Homeost. Agents 2019, 33, 1651-1656. [CrossRef]

51. Scarano, A.; de Oliveira, P.S.; Traini, T.; Lorusso, F. Sinus Membrane Elevation with Heterologous Cortical Lamina: A Randomized Study of a New Surgical Technique for Maxillary Sinus Floor Augmentation without Bone Graft. Materials 2018, 11 , 1457. [CrossRef]

52. Scarano, A.; Murmura, G.; Mastrangelo, F.; Lorusso, F.; Greco Lucchina, A.; Carinci, F. A Novel Technique to Prevent Sinus Membrane Collapse during Maxillary Sinus Floor Augmentation without Bone Graft: Technical Note. J. Biol. Regul. Homeost. Agents 2018, 32, 1589-1592. [PubMed]

53. Borges, F.L.; Dias, R.O.; Piattelli, A.; Onuma, T.; Gouveia Cardoso, L.A.; Salomão, M.; Scarano, A.; Ayub, E.; Shibli, J.A. Simultaneous Sinus Membrane Elevation and Dental Implant Placement without Bone Graft: A 6-Month Follow-up Study. J. Periodontol. 2011, 82, 403-412. [CrossRef] [PubMed]

54. Rigo, L.; Viscioni, A.; Franco, M.; Lucchese, A.; Zollino, I.; Brunelli, G.; Carinci, F. Overdentures on Implants Placed in Bone Augmented with Fresh Frozen Bone. Minerva Stomatol. 2011, 60, 5-14. [CrossRef] [PubMed] 
55. Lucchese, A.; Carinci, F.; Brunelli, G.; Monguzzi, R. Everstick ${ }^{\circledR}$ and Ribbond ${ }^{\circledR}$ Fiber Reinforced Composites: Scanning Electron Microscope (SEM) Comparative Analysis. Eur. J. Inflamm. 2011, 3, 17.

56. Roncati, M.; Polizzi, E.; Cingano, L.; Lucchese, A. An Oral Health Aid for Disabled Patients. Dent. Cadmos. 2013, 81, 447-452. [CrossRef]

57. Rodriguez y Baena, R.; Pastorino, R.; Gherlone, E.F.; Perillo, L.; Lupi, S.M.; Lucchese, A. Histomorphometric Evaluation of Two Different Bone Substitutes in Sinus Augmentation Procedures: A Randomized Controlled Trial in Humans. Int. J. Oral Maxillofac. Implants 2017, 32, 188-194. [CrossRef]

58. Velasco-Torres, M.; Padial-Molina, M.; Avila-Ortiz, G.; García-Delgado, R.; O’Valle, F.; Catena, A.; Galindo-Moreno, P. Maxillary Sinus Dimensions Decrease as Age and Tooth Loss Increase. Implant Dent. 2017, 26, 288-295. [CrossRef]

59. Bertossi, D.; Giampaoli, G.; Lucchese, A.; Manuelli, M.; Albanese, M.; Nocini, R.; Nocini, P.F. The Skin Rejuvenation Associated Treatment-Fraxel Laser, Microbotox, and Low G Prime Hyaluronic Acid: Preliminary Results. Lasers Med. Sci. 2019, 34, 1449-1455. [CrossRef]

60. Manuelli, M. A Peaceful Man. Prog. Orthod. 2012, 13, 1. [CrossRef]

61. Prati, C.; Chersoni, S.; Lucchese, A.; Pashley, D.H.; Mongiorgi, R. Dentin Permeability after Toothbrushing with Different Toothpastes. Am. J. Dent. 1999, 12, 190-193.

62. Palmieri, A.; Zollino, I.; Clauser, L.; Lucchese, A.; Girardi, A.; Farinella, F.; Carinci, F. Biological Effect of Resorbable Plates on Normal Osteoblasts and Osteoblasts Derived From Pfeiffer Syndrome. J. Craniofacial Surg. 2011, 22, 860-863. [CrossRef]

63. Danza, M.; Zollino, I.; Avantaggiato, A.; Lucchese, A.; Carinci, F. Distance between Implants Has a Potential Impact of Crestal Bone Resorption. Saudi Dent. J. 2011, 23, 129-133. [CrossRef]

64. Lucchese, A.; Manuelli, M. Prognosis of Third Molar Eruption: A Comparison of Three Predictive Methods. Prog. Orthod. 2003, 4, 4-19.

65. Lucchese, A.; Porcù, F.; Dolci, F. Effects of Various Stripping Techniques on Surface Enamel. J. Clin. Orthod. 2001, 35, 691-695. [PubMed]

66. Almas, K.; Smith, S.; Kutkut, A. What Is the Best Micro and Macro Dental Implant Topography? Dent. Clin. N. Am. 2019, 63, 447-460. [CrossRef] [PubMed]

67. Matarese, G.; Isola, G.; Ramaglia, L.; Dalessandri, D.; Lucchese, A.; Alibrandi, A.; Fabiano, F.; Cordasco, G. Periodontal biotype: Characteristic, prevalence and dimensions related to dental malocclusion. Minerva Stomatol. 2016, 65, 231-238. [PubMed]

68. Lo Giudice, A.; Ortensi, L.; Farronato, M.; Lucchese, A.; Lo Castro, E.; Isola, G. The step further smile virtual planning: Milled versus prototyped mock-ups for the evaluation of the designed smile characteristics. BMC Oral Health 2020, 20, 165. [CrossRef] [PubMed] 